\title{
Prevalence and Characteristics of Musculoskeletal Pain in Korean Farmers
}

\begin{abstract}
David Min, MD ${ }^{1,2}$, Sora Baek, MD, PhD ${ }^{1,2,3}$, Hee-won Park, MD ${ }^{1,2,3,4}$, Sang-Ah Lee, PhD ${ }^{1,5}$, Jiyoung Moon, PhD ${ }^{1,6}$, Jae E. Yang, PhD ${ }^{1,7}$, Ki Sung Kim, PhD ${ }^{1,8}$, Jee Yong Kim, PhD ${ }^{1,9,10}$, Eun Kyoung Kang, MD, PhD ${ }^{1,2,3}$

${ }^{1}$ Center for Farmer's Safety and Health, Kangwon National University Hospital, Chuncheon; ${ }^{2}$ Department of Rehabilitation Medicine, Kangwon National University Hospital, Chuncheon; ${ }^{3}$ Department of Rehabilitation Medicine, Kangwon National University School of Medicine, Chuncheon; ${ }^{4}$ Gangwon-Do Rehabilitation Hospital, Chuncheon; ${ }^{5}$ Department of Preventive Medicine, Kangwon National University School of Medicine, Chuncheon; ${ }^{6}$ Department of Preventive Medicine, Kangwon National University Hospital, Chuncheon; ${ }^{7}$ Department of Biological Environment, Kangwon National University, Chuncheon; ${ }^{8}$ Department of Regional Infrastructure Engineering, Kangwon National University, Chuncheon; ${ }^{9}$ NongTeo Co. Ltd., Chuncheon; ${ }^{10}$ Gangwon Rural Revitalization Support Center, Chuncheon, Korea
\end{abstract}

Objective To investigate the prevalence and characteristics of musculoskeletal pain (MSK) pain in Korean farmers using initial survey data of Farmers' Cohort for Agricultural Work-Related MSK pain (FARM) study.

Methods Farmers (534 females and 479 males; mean age 57.2 \pm 7.5 years) who owned or rented a farm and belonged to an agricultural cooperative unit were recruited. Presence of pain for each body part (neck, shoulder, arm/elbow, wrist/hand/finger, low back, leg/foot), and characteristics of MSK pain (prevalence, location, duration, severity, and frequency) during the last year was assessed. Additionally, demographic data such as farming duration, history of prior injury, and workload (low, moderate, somewhat hard, or hard) were collected using structured questionnaires.

Results Almost all subjects ( $\mathrm{n}=925 ; 91.3 \%$ ) complained of pain in more than one body part. The frequency order was low back (63.8\%), leg/foot (43.3\%), shoulder (42.9\%), wrist/hand/finger (26.6\%), arm/elbow (25.3\%), and neck $(21.8 \%)$. Low back pain was more frequent in those with over 30 years of farming experience (odds ratio [OR], $1.40 ; 95 \%$ confidence interval, $1.08-1.81)$. MSK pain was related to history of prior injury $(O R, 2.18-5.24 ; \mathrm{p}<0.05)$ in all body parts except for leg/foot, and very hard workload was associated with low back, leg/foot, neck, shoulder, and wrist/hand/finger pain (OR, 2.88-10.83; $\mathrm{p}<0.05)$.

Conclusion Most Korean farmers experience MSK pain; furthermore, there is a significant association between pain, history of prior injury, and workload, suggestive of the necessity of coping and preventive strategies to reduce injury or workload.

Keywords Agriculture, Musculoskeletal pain, Low back pain, Injuries, Workload

Received April 8, 2015; Accepted August 7, 2015

Corresponding author: Eun Kyoung Kang

Department of Rehabilitation Medicine, Kangwon National University Hospital, 156 Baengnyeong-ro, Chuncheon 24289, Korea Tel: +82-33-258-9205, Fax: +82-33-258-2146, E-mail: stewardofgod@gmail.com

(c) This is an open-access article distributed under the terms of the Creative Commons Attribution Non-Commercial License (http://creativecommons.org/ licenses/by-nc/4.0) which permits unrestricted noncommercial use, distribution, and reproduction in any medium, provided the original work is properly cited. Copyright $\odot 2016$ by Korean Academy of Rehabilitation Medicine 


\section{INTRODUCTION}

Farmers are at particular risk of developing agricultural work-related musculoskeletal (MSK) pain, because farming work consists of strenuous physical activities and high levels of manual labor, which has been considered a high-risk occupation for MSK disorders [1-3]. Likewise, Walker-Bone and Palmer [4] suggested that several physical risk factors for MSK pain (such as lifting and carrying heavy loads, work with the trunk flexed, and exposure to whole-body vibration) were present more frequently among farmers, and farmers more often have knee osteoarthritis and low back pain, as compared to the workers in occupations with fewer physical demands.

Agricultural work-related MSK pain may lead to further negative consequences such as reduced work ability, lower farm income, poorer quality of life, and the onset of other health problems such as stress or depression. Since medical expenses and loss of the labor force are enormous, developed countries have started to pay attention to these problems $[5,6]$. In Korea, regulation for prevention and management of MSK pain was established by law; however, the priority was industrial manufacturing business and did not include farmers as a result of their comparatively small numbers and cultivation [7]. Studies on the prevalence and characteristics of MSK pain and its related risk factors are required to improve the health condition of farmers, as well as the supportive legislative system.

Several studies have focused on MSK in Korean farmers. Sun et al. [8] reported that almost all recruited Korean farmers had pain and discomfort in their back, shoulders, or arms, but they did no use structured questionnaire. Lee [2] reported high rates of MSK such as back pain and knee osteoarthritis, however, they were unable to distinguish the influence between work-related and natural aging effects. Another systemic survey about the work-related MSK among the dairy farmers showed that the prevalence of MSK pain at any body site was $33.3 \%$ suggesting limited application to general farmers due to the relatively low population of dairy farmers [3]. In terms of agricultural work-related injuries, several studies only reported incidence and cause of injuries, and did not show the association between MSK pain and related injuries $[9,10]$. Thus, systematic survey on MSK pain and related factors (sociodemographic, health characteristics and agricultural work-related factors) is needed.

Therefore, the purpose of this study was to examine the prevalence and characteristics of agricultural workrelated MSK pain, and its association with farming duration, history of prior injury, workload, and type of farming among Korea farmers based on a large sample and a standard questionnaire developed by the Korean Occupational Safety and Health Agency (KOSHA) [11]

\section{MATERIALS AND METHODS}

\section{Subjects}

We performed a cross-sectional analysis for initial survey data of Farmers' Cohort for Agricultural Work-Related MSK pain (FARM) study [12], which recruited active farmers who owned or rented a farm and belonged to an agricultural cooperative unit. Local representatives of the National Agricultural Cooperative Federation verified farmer status. The study took place from September 2013 to June 2014. A total of 1,027 farmers in the Gangwon province in South Korea completed the survey. Fourteen subjects (4 amputees, 1 very low weight individual [37.7 $\mathrm{kg}$ ], and 9 non-farmers) were excluded. Thus, a total of 1,013 subjects were included in the analysis (Fig. 1).

This study was conducted by the Center for Farmers' Safety and Health at Kangwon National University Hospital, and was approved by the Institutional Review Board of the Kangwon National University Hospital (IRB No. 2013-06-009-007). Written informed consent was obtained from all participants in the study.

\section{Ouestionnaire}

Age ( $<65$ vs. $\geq 65$ years), gender, farming period ( $<30$ vs. $\geq 30$ years), previous employment period (years), marital status (single/married), working hours a day $(<10,10-12$, $\geq 12$ hours), regular leisure activities, housework time per

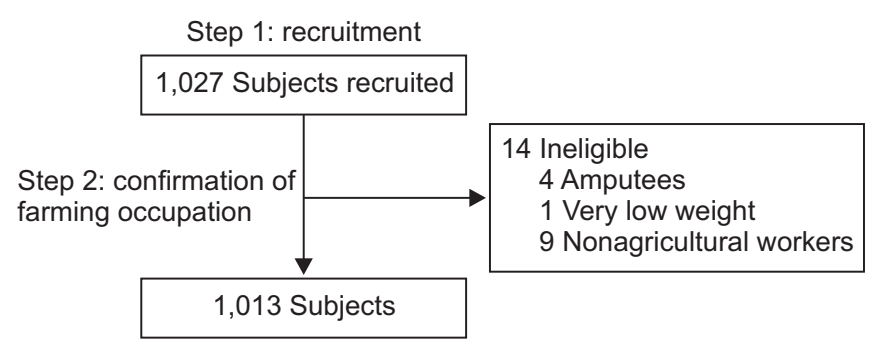

Fig. 1. Inclusion flowchart. 
day (rarely, $<1,1-2,2-3, \geq 3$ hours), history of prior injury (yes/no), injury location (neck, shoulder, arm/elbow, wrist/hand/finger, low back, leg/foot), and severity of workload (low, moderate, somewhat hard, very hard) of the research subjects were surveyed using a structured questionnaire. In addition, type of farming was classified into 4 types: rice farming (rice), dry fields farming (e.g., corn, potato), greenhouses farming (e.g., cucumber, tomato), and orchards farming (e.g., apple, peach).

The questionnaire was the standard questionnaire for one-year self-reported prevalence and characteristics of MSK pain, which was developed by the KOSHA [11]. The case definition of MSK symptoms was as follows: 1) those who felt musculoskeletal symptoms during the past 12 months in any body part, and 2) the symptom lasted over a week or the symptom was observed more than once a month during the past year.

Respondents were asked to answer questions about presence of pain (yes or no), pain location (neck, neck, shoulder, arm/elbow, wrist/hand/finger, low back, leg/ foot), specific side of pain (left/right/both), duration ( $<1$ day, 1 day- 1 week, 1 week- 1 month, 1 month-6 months, $\geq 6$ months), severity (mild, moderate, severe, very severe), frequency (semiannually, quarterly, monthly, weekly, daily), presence of pain within 1 week (yes or no), and consequence of pain (visit clinic, visit pharmacy, sick leave, change job, do nothing or etc.) during the past 12 months.

\section{Statistics}

Statistical analyses were conducted using SPSS ver. 21.0 (IBM, Armonk, NY, USA) and the detailed statistical methodology was as follows. Descriptive statistics were conducted to analyze the subjects' general characteristics and frequency of pain characteristics. Logistic regression analysis was used to calculate the odds ratio (OR) of various risk factors with respect to each body part where MSK pain was present. Significance was accepted at $\mathrm{p}<0.05$ and $95 \%$ confidence intervals (CI) were calculated. Variables with $\mathrm{p}<0.20$ in univariate analyses were examined in multivariate binary logistic regression models.

\section{RESULTS}

The average age of the 1,013 subjects was $57.15 \pm 7.52$ years old. Of all subjects, 479 (47.3\%) were male and 534
(52.7\%) were female. In addition, $78.8 \%$ of farmers were under 65 years old, which is relatively high. Farmers who had worked longer than 30 years made up $53.0 \%$ of the sample, 361 (35.6\%) had history of injury. The total number of subjects who undertook no regular leisure activities was 895 (88.4\%). Eighteen (1.8\%) male farmers worked $\geq 3$ hours a day in the home, as compared to 225 $(22.2 \%)$ of female farmers who did so. Of those reporting a very hard workload, 225 (22.2\%) were female and 141 (13.9\%) were male. Females reported longer amounts of time doing housework $\left(\chi^{2}=584.84, \mathrm{p}<0.01\right)$, and felt their work was hard more often than males $\left(\chi^{2}=24.00, p<0.01\right)$. Other demographic characteristics were described in Table 1.

Frequency analysis of the symptoms of musculoskeletal disorder revealed 925 subjects (91.3\%) had pain in $\geq 1$ area. The 1-year prevalence rates for MSK were as follows: low back (63.8\%), leg/foot (43.3\%), shoulder (42.9\%), wrist/hands/finger (26.6\%), arm/elbow (25.3\%), and neck (21.8\%). Thus, the low back was the most affected anatomical region. In terms of frequency of daily pain, the order was neck (30.3\%), shoulder (42.8\%), arm/elbow $(41.0 \%)$, wrist/hand/finger (43.1\%), low back (43.8\%), and leg/foot (48.7\%). For all body parts, pain duration of 1 day- 1 week was most common, followed by $\leq 6$ months. Neck (39.8\%), shoulder (38.4\%), low back (34.8\%), arm/ elbow (30.5\%), wrist/hand/finger (30.5\%), and leg/foot (30.1\%) had 1 day-1 week pain duration; and low back (31.1\%), leg/foot (29.6\%), wrist/hand/finger (29.4\%), arm/elbow (27.7\%), shoulder (26.4\%), and neck (21.7\%) had pain duration of $\geq 6$ months. Regarding the severity of pain, a moderate degree of MSK pain was most common in all body parts as follows: low back (45.8\%), leg/ foot (44.9\%), shoulder (44.4\%), arm/elbow (44.1\%), neck (41.6\%), and wrist/hand/finger (41.6\%).

Concerning the frequency of pain, pain for approximately 1-7 days was also most common in the neck (39.8\%), shoulder (38.4\%), low back (34.8\%), arm/elbow (30.5\%), wrist/hand/finger (30.5\%), and leg/foot (30.1\%). Health care consultation as a consequence of MSK pain was most frequently visiting a clinic for all body parts: low back (59.4\%), leg/foot (54.0\%), shoulder (51.0\%), neck (48.4\%), arm/elbow (43.4\%), and wrist/hand/finger (36.1\%). However, although many subjects had MSK pain, most did nothing to overcome their pain in the wrist/hand/finger (39.8\%), arm/elbow (36.7\%), neck 
Table 1. Demographic characteristics of enrolled subjects

\begin{tabular}{|c|c|}
\hline Variable & Female \\
\hline Sex & $479(47.3) \quad 534(52.7)$ \\
\hline Age (yr) & $57.2 \pm 7.5$ \\
\hline$<65$ & $798(78.8)$ \\
\hline$\geq 65$ & $215(21.2)$ \\
\hline Farming period (yr) & $27.8 \pm 14.1$ \\
\hline$<30$ & $476(47.0)$ \\
\hline$\geq 30$ & $537(53.0)$ \\
\hline \multicolumn{2}{|l|}{ Marital status } \\
\hline Single & $90(8.9)$ \\
\hline Married & $923(91.1)$ \\
\hline \multicolumn{2}{|l|}{ Working time per day (hr) } \\
\hline$<10$ & $162(16.0) \quad 186(18.4)$ \\
\hline $10-12$ & $114(11.3) \quad 121(11.9)$ \\
\hline$\geq 12$ & $203(20.0) 227(22.4)$ \\
\hline Previous employment period (yr) & $5.2 \pm 9.0$ \\
\hline \multicolumn{2}{|l|}{ Regular leisure activities } \\
\hline No regular leisure activities & $895(88.4)$ \\
\hline Computer-related & $47(4.6)$ \\
\hline $\begin{array}{l}\text { Musical instrument } \\
\text { (piano, violin, etc.) }\end{array}$ & $22(2.2)$ \\
\hline Crochet, calligraphy & $15(1.5)$ \\
\hline Tennis/badminton/squash & $19(1.9)$ \\
\hline $\begin{array}{l}\text { Football/basketball/ski/ } \\
\text { foot volley ball }\end{array}$ & $15(1.5)$ \\
\hline \multicolumn{2}{|l|}{ House working time per day (hr) } \\
\hline Rarely & $250(24.7)$ \\
\hline$<1$ & $143(14.1)$ \\
\hline $1-2$ & $56(5.5) \quad 152(15.0)$ \\
\hline $2-3$ & $109(10.8)$ \\
\hline$\geq 3$ & $18(1.8) \quad 225(22.2)$ \\
\hline \multicolumn{2}{|l|}{ History of injury } \\
\hline No & $652(61.7)$ \\
\hline Yes & $361(35.6)$ \\
\hline \multicolumn{2}{|l|}{ Workload } \\
\hline Low & $15(1.5)$ \\
\hline Moderate & $186(18.4) \quad 144(14.2)$ \\
\hline Somewhat hard & $129(12.7) \quad 154(15.2)$ \\
\hline Very hard & $141(13.9) 221(21.8)$ \\
\hline \multicolumn{2}{|l|}{ Type of farming } \\
\hline Rice farming & $157(15.5)$ \\
\hline Dry fields farming & $420(41.5)$ \\
\hline Greenhouses farming & $311(30.7)$ \\
\hline Orchards farming & $125(12.3)$ \\
\hline
\end{tabular}

Values are presented as number (\%) or mean \pm standard deviation.
(31.2\%), leg/foot (29.4\%), shoulder (28.7\%), and low back (23.4\%) (Table 2).

Our results indicated that subjects aged over 65 years had more leg/foot (OR, 1.49; 95\% CI, 1.10-2.02; $\mathrm{p}=0.009$ ) pain than those under 65 . However, this result was not statistically significant for neck, shoulder, arm/elbow, wrist/hand/finger and low back pain. Significant associations between MSK pain and history of prior injury were found for the neck (OR, 4.65; 95\% CI, 2.61-8.29; $\mathrm{p}<0.001$ ), shoulder (OR, 2.18; 95\% CI, 1.18-4.06; $\mathrm{p}<0.001$ ), arm/elbow (OR, 2.29; 95\% CI, 1.55-5.25; $\mathrm{p}<0.001$ ), wrist/ hand/finger (OR, 2.70; 95\% CI, 1.62-4.53; $\mathrm{p}<0.001)$, and low back (OR, 5.24; 95\% CI, 2.76-9.94; $<<0.001)$. The only non-significant relationship was for the leg/foot (OR, 1.00; 95\% CI, 0.68-1.47; $\mathrm{p}=0.540$ ). The influence of a very hard workload on the prevalence of pain was significant for MSK pain in the shoulder (OR, 2.89; 95\% CI, 1.37-6.13; $\mathrm{p}=0.006)$, wrist/hand/finger (OR, 2.88; 95\% CI, 1.10-7.58; $\mathrm{p}=0.032$ ), low back (OR, 10.83; 95\% $\mathrm{CI}, 4.93-23.79 ; \mathrm{p}<0.001)$, and leg/foot (OR, 3.92; 95\% CI, 1.75-8.78; $\mathrm{p}<0.001)$. Relative risk of dry fields farming was 1.64 times higher than rice farming (OR, 1.64; 95\% CI, 1.02-2.63; $p=0.042$ ). Female farmers showed higher prevalence of pain in the neck (OR, 1.83; 95\% CI, 1.35-2.50; $\mathrm{p}<0.001$ ), shoulder (OR, 2.12; 95\% CI, 1.64-2.73; $\mathrm{p}<0.001$ ), wrist/hand/finger (OR, 3.39; 95\% CI, 2.49-4.60; $<<0.001$ ), low back (OR, 2.20, 95\% CI, 1.69-2.85; p<0.001) and leg/ foot (OR, 2.04; 95\% CI, 1.58-2.63; $\mathrm{p}<0.001$ ). The only body part that was non-significant was the arm/elbow. Low back pain was more prevalent among those in the $>30$ years of farming period group than in the $<30$ years group (OR, 1.40; 95\% CI, 1.08-1.81). However, the prevalence of MSK pain in the neck (OR, 0.64; 95\% CI, 0.48-0.87) and wrist/hand/finger (OR, 0.71; 95\% CI, 0.54-0.94) were lower in subjects who were engaged in farming over 30 years. Working $>12$ hours a day was a significant contributing factor to wrist/hand/finger pain (OR, 1.50; 95\% CI, 1.09-2.07) (Table 3).

Multivariate analysis indicated that the prevalence of neck pain was significant for $>30$ years of farming duration, 2-3 hours of work in the home, presence of prior injury, and very hard workload. Shoulder pain was more prevalent among females, subjects with history of prior injury, and those with a very hard workload. Doing $>3$ hours of housework a day and history of prior injury remained factors significantly related to arm/elbow pain. 
Table 2. Prevalence and characteristics of one-year self-reported musculoskeletal pain

\begin{tabular}{|c|c|c|c|c|c|c|}
\hline \multirow[b]{2}{*}{ Variable } & \multicolumn{6}{|c|}{ Pain } \\
\hline & Neck & Shoulder & Arm/elbow & $\begin{array}{l}\text { Wrist/hand/ } \\
\text { finger }\end{array}$ & Low back & Leg/foot \\
\hline No & $792(78.2)$ & $578(57.1)$ & 757 (74.7) & 744 (73.4) & 367 (36.2) & $574(56.7)$ \\
\hline Yes & $221(21.8)$ & 435 (42.9) & $256(25.3)$ & 269 (26.6) & $646(63.8)$ & $439(43.3)$ \\
\hline \multicolumn{7}{|l|}{ Location } \\
\hline Right & - & $123(28.3)$ & $98(38.3)$ & $68(25.3)$ & - & $108(24.6)$ \\
\hline Left & - & 79 (18.2) & $39(15.2)$ & $30(11.2)$ & - & $94(21.4)$ \\
\hline Both & - & $216(49.7)$ & $105(41.0)$ & $153(56.9)$ & - & $199(45.3)$ \\
\hline Non-response & - & $17(3.9)$ & $14(5.5)$ & $18(6.7)$ & - & $38(8.7)$ \\
\hline \multicolumn{7}{|l|}{ Duration } \\
\hline$<1$ day & $56(25.3)$ & $93(21.4)$ & $67(26.2)$ & $63(23.4)$ & $124(19.2)$ & $115(26.2)$ \\
\hline 1 day-1 wk & $88(39.8)$ & $167(38.4)$ & $78(30.5)$ & $82(30.5)$ & $225(34.8)$ & $132(30.1)$ \\
\hline $1 \mathrm{wk}-1 \mathrm{mo}$ & $22(10.0)$ & 37 (8.5) & $22(8.6)$ & $26(9.7)$ & $65(10.1)$ & $33(7.5)$ \\
\hline $1-6 \mathrm{mo}$ & $6(2.7)$ & $19(4.4)$ & $17(6.6)$ & $16(5.9)$ & $29(4.5)$ & $23(5.2)$ \\
\hline$\geq 6 \mathrm{mo}$ & $48(21.7)$ & $115(26.4)$ & $71(27.7)$ & $79(29.4)$ & $201(31.1)$ & $130(29.6)$ \\
\hline Non-response & $1(0.5)$ & $4(0.9)$ & $1(0.4)$ & $3(1.1)$ & $2(0.3)$ & $6(1.4)$ \\
\hline \multicolumn{7}{|l|}{ Severity } \\
\hline Mild & 78 (35.3) & $132(30.3)$ & $85(33.2)$ & 99 (36.8) & 127 (19.7) & $133(30.3)$ \\
\hline Moderate & $92(41.6)$ & $193(44.4)$ & $113(44.1)$ & $112(41.6)$ & $296(45.8)$ & $197(44.9)$ \\
\hline Severe & $46(20.8)$ & 97 (22.3) & $52(20.3)$ & $48(17.8)$ & $186(28.8)$ & $92(21.0)$ \\
\hline Very severe & $3(1.4)$ & $13(3.0)$ & $5(2.0)$ & $8(3.0)$ & $33(5.1)$ & $16(3.6)$ \\
\hline Non-response & $2(0.9)$ & $0(0.0)$ & $1(0.4)$ & $2(0.7)$ & $4(0.6)$ & $1(0.2)$ \\
\hline \multicolumn{7}{|l|}{ Frequency } \\
\hline Semiannually & $22(10.0)$ & $29(6.7)$ & $15(5.9)$ & $19(7.1)$ & $52(8.0)$ & $35(8.0)$ \\
\hline Quarterly & $36(16.3)$ & $67(15.4)$ & $39(15.2)$ & $30(11.2)$ & $92(14.2)$ & $54(12.3)$ \\
\hline Monthly & $39(17.6)$ & $65(14.9)$ & $36(14.1)$ & $43(16.0)$ & $90(13.9)$ & $72(16.4)$ \\
\hline Weekly & $54(24.4)$ & $86(19.8)$ & $59(23.0)$ & $58(21.6)$ & $125(19.3)$ & $61(13.9)$ \\
\hline Daily & $67(30.3)$ & $186(42.8)$ & $105(41.0)$ & $116(43.1)$ & $283(43.8)$ & $214(48.7)$ \\
\hline Non-response & $3(1.4)$ & $2(0.5)$ & $2(0.8)$ & $3(1.1)$ & $4(0.6)$ & $3(0.7)$ \\
\hline \multicolumn{7}{|c|}{ Presence of pain within $1 \mathrm{wk}$} \\
\hline Yes & $150(67.9)$ & $317(72.9)$ & $185(72.3)$ & $200(74.3)$ & $468(72.4)$ & $330(75.2)$ \\
\hline No & $68(30.8)$ & $116(26.7)$ & $69(27.0)$ & $68(25.3)$ & $172(26.6)$ & $106(24.1)$ \\
\hline Non-response & $3(1.4)$ & $2(0.5)$ & $2(0.8)$ & $1(0.4)$ & $6(0.9)$ & $3(0.7)$ \\
\hline \multicolumn{7}{|l|}{ Consequence of pain } \\
\hline Visit clinic & $107(48.4)$ & $222(51.0)$ & $111(43.4)$ & $97(36.1)$ & $384(59.4)$ & $237(54.0)$ \\
\hline Visit pharmacy & $17(7.7)$ & $32(7.4)$ & $15(5.9)$ & $18(6.7)$ & $34(5.3)$ & $24(5.5)$ \\
\hline Sick leave & $16(7.2)$ & $29(6.7)$ & $22(8.6)$ & $26(9.7)$ & $46(7.1)$ & $29(6.6)$ \\
\hline Change job & $5(2.3)$ & $10(2.3)$ & $4(1.6)$ & $6(2.2)$ & $6(0.9)$ & $5(1.1)$ \\
\hline Do nothing & $69(31.2)$ & $125(28.7)$ & $94(36.7)$ & $107(39.8)$ & $151(23.4)$ & $129(29.4)$ \\
\hline Etc. & $5(2.3)$ & $11(2.5)$ & $5(2.0)$ & $8(3.0)$ & $17(2.6)$ & $10(2.3)$ \\
\hline Non-response & $2(0.9)$ & $6(1.4)$ & $5(2.0)$ & $7(2.6)$ & $8(1.2)$ & $5(1.1)$ \\
\hline
\end{tabular}

Values are presented as number (\%). 


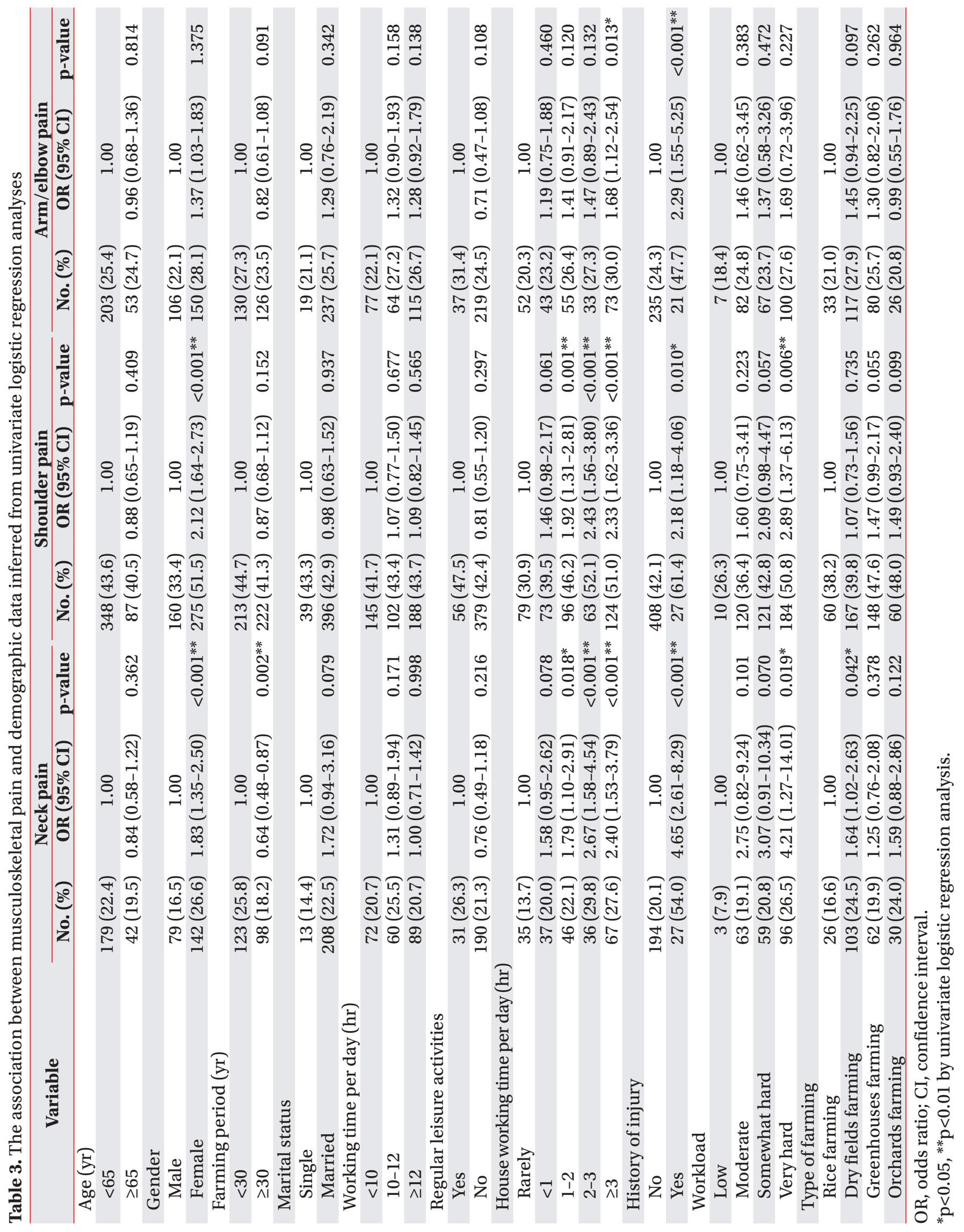




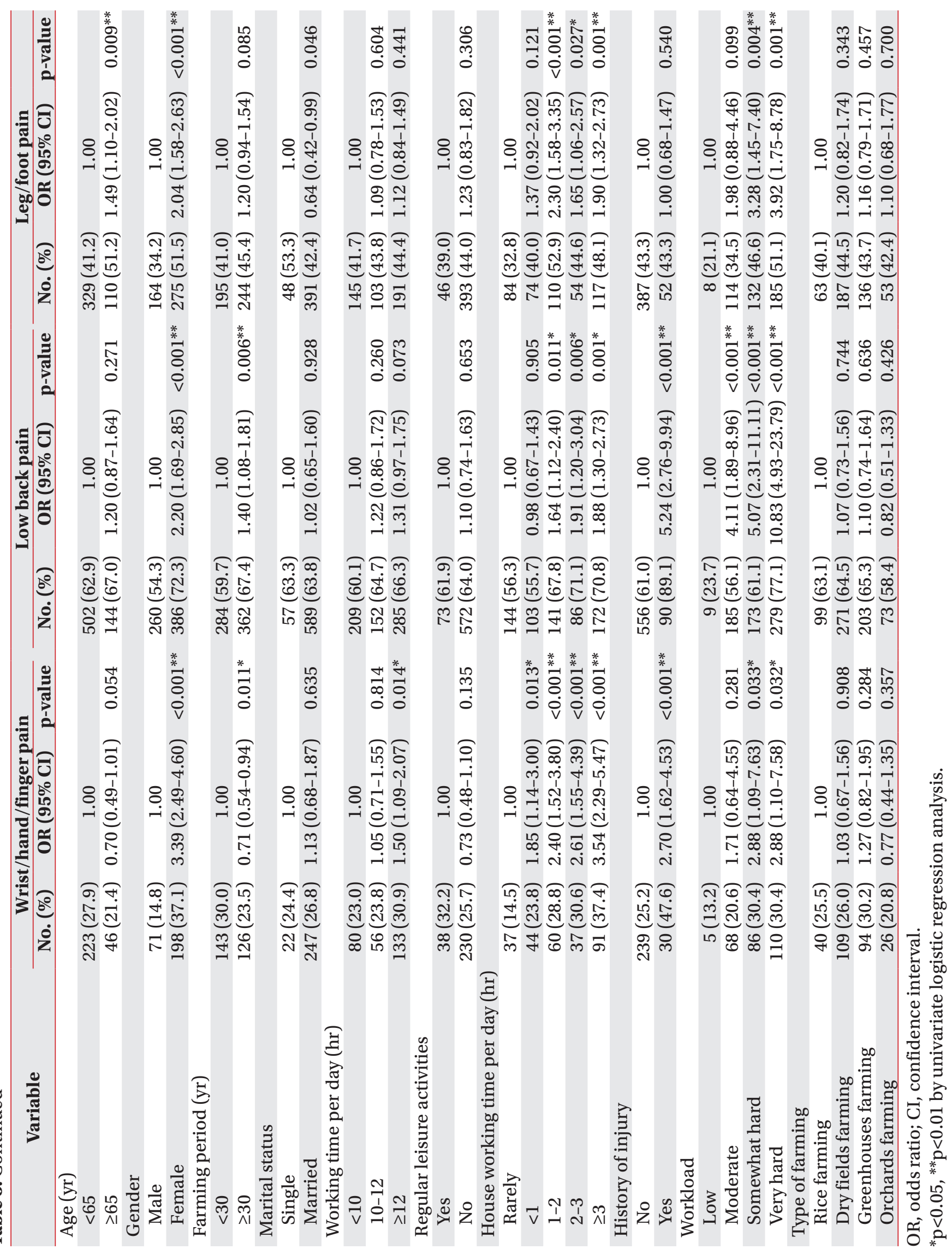




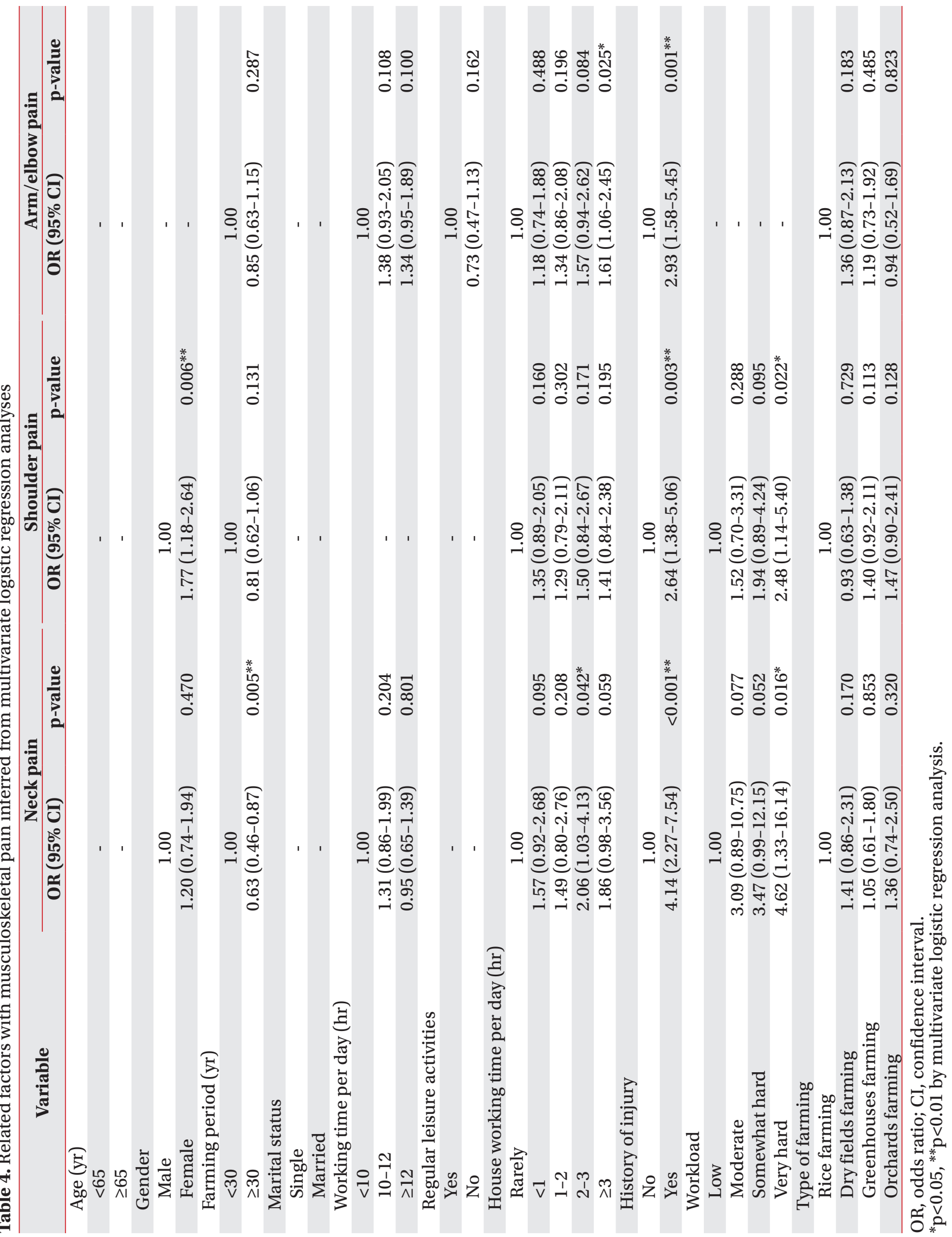




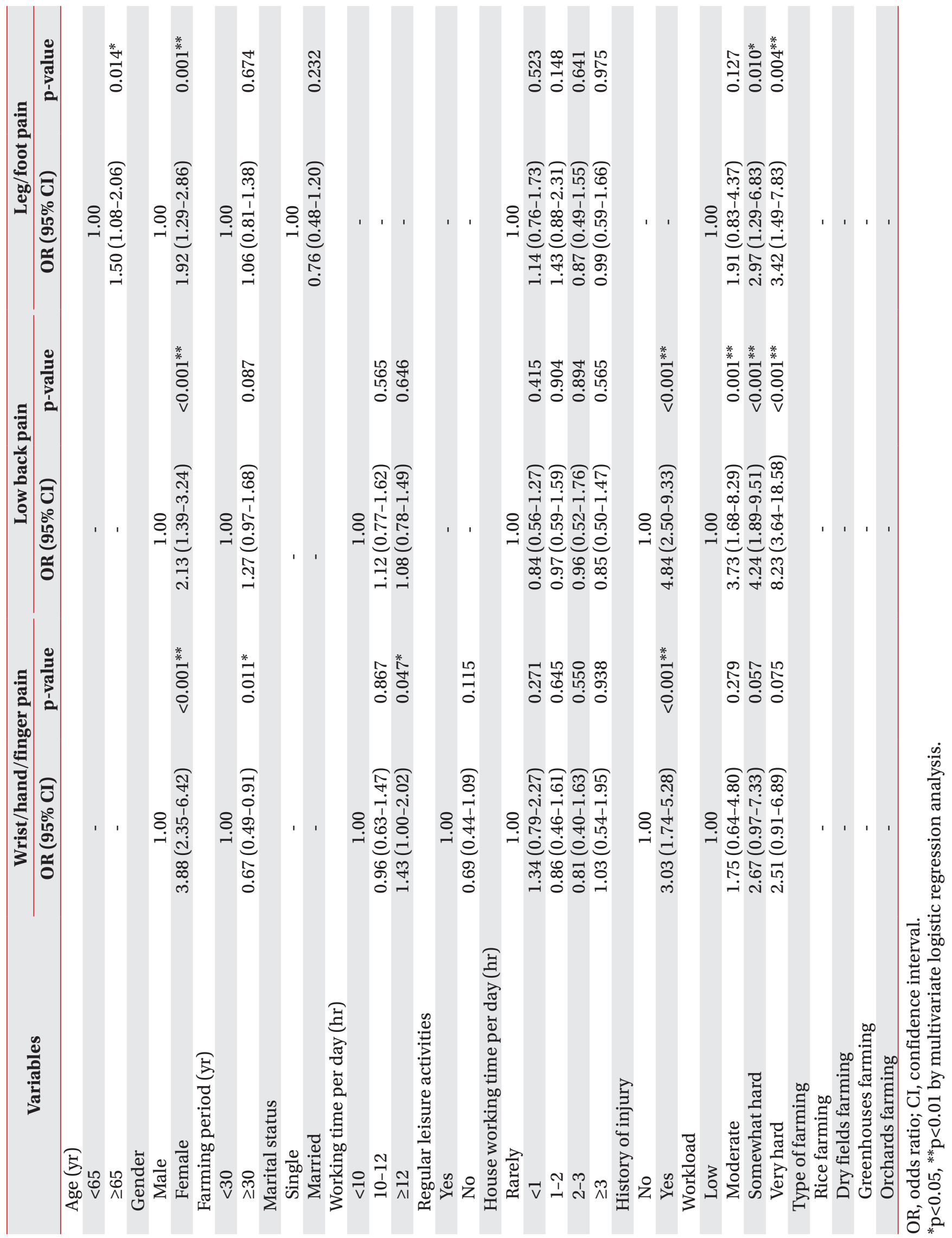


For wrist/hand/finger pain key, factors included being female, over 30 years of farming period, working over 12 hours a day, history of prior injury were related, and for low back pain key, female, history of prior injury, and workload severity were related significantly. For pain in the leg/foot, related factors included old age, female gender, and very hard workload. Table 4 listed the result of multivariate logistic regression analysis for each factor.

\section{DISCUSSION}

Farming is a physically arduous occupation and many farmers are at potential risk of developing MSK pain because of chronic cumulative or high intensity workload. The purpose of this study was to verify the prevalence and characteristics of MSK pain in Korean farmers. Previous studies using the KOSHA structured questionnaire reported that Korean farmers showed higher prevalence of MSK pain than other occupational clusters in Korea during the previous 12 months [13-16]. Many agricultural workloads are physically very strenuous because of the repetitive motions, awkward postures, forceful exertion, and stress level, and farmers are at particular risk of developing MSK pain, as compared with other workers $[4,17,18]$.

Previous systematic review for prevalence of MSK disorders among farmers reported that low back is the most common painful body region followed by upper and then lower extremity, and the prevalence of MSK disorder in farmers is greater than in non-farmers [19]. In this study, the most frequent painful body part was also low back, followed by the leg/foot and shoulder. The pain location may be different according to the body part used, degree of muscle activity, and working environment [20]. The National Institute for Occupational Safety and Health reported that repeated work, excessive force, and improper working postures cumulatively affected MSK system symptoms in the arm/wrist/hand region. Furthermore, the neck/shoulder region was affected by improper working postures, and the lumbar region was affected by lifting, hard physical work, or systemic vibrations [21]. Therefore, we can easily assume the farming activities are related to pain in various body parts, and then recommend coping strategies or modifications for risky farming activities.

Workload is also known to be a significant risk factor for MSK pain [22]. Oliveira Dantas and de Lima [23] assessed the relationship between physical load and MSK complaints among dentists; they concluded that there was a high prevalence of MSK complaints and significant associations with variables related to physical workload. Our study also demonstrates that the prevalence of pain in body parts (except arm/elbow) was closely related to agricultural workload. Furthermore, these associations between workload and pain in the neck, shoulder, low back, and leg/foot were also detected on multivariate analysis. Thus, workload is a powerful predictor of MSK pain.

In terms of gender differences, female farmers were found to complain of more frequent [15] and severe pain, as compared to males [24]. In the study sample, there were significant associations between being female and MSK pain in most body parts except for the arm/ elbow. Similarly, in the present study, the same results were found for females. Consequently, this may explain the gender difference of higher physical vulnerability or sensitivity to pain among women $[14,15,25]$. Kilbom and Messing [26] discussed potential reasons for higher MSK morbidity rates among female workers. One such reason is that, outside of work, females may be more frequently exposed to risk factors for MSK pain during household and childcare activities than males. In this study, females did housework for a longer time and reported harder work experience than males. Thus, we can expect that many women must cope with the housework and a job that are known to contribute to the proportion of MSK pain $[16,25]$.

Recently the mechanization of agriculture has made many farmers, especially rice farmers, use farming machinery because of the characteristics of land in relatively even level. However, farmers of dry farming still need to use their bodies in agricultural work instead of farming machinery, and work in squat posture for a long time. In our study, farmers of dry farming complained of neck pain significantly more than those of rice farming, suggesting the different characteristics of agricultural work according to the types of farming and the need for further study considering the ergonomic factors.

Regarding the workload, pain in lower extremities and low back tended to increase with workload increase, while pain in upper extremities was influenced little by the workload. In terms of role of body in farming, upper 
extremities are used in repetitive motions or handling, while low back and lower extremities support the body weight. These results may show the indirect association between workload and weight-supporting agricultural works.

Over the years, several cross-sectional studies on MSK complaints have reported a sharp increase in prevalence rates with workers' advancing age. However, in this study, prevalence of MSK pain for subjects under 65 years old and over 65 years old was no different, except in terms of leg/foot pain. A possible explanation for this observation is that other factors are more strongly related to MSK. In the case of low back pain, MSK symptoms increased significantly as farming duration increased; therefore, we could expect that this is because older people have longer farming duration $[2,10]$.

Although it is generally accepted that gaining more experience and older age may lead to more frequent MSK pain, this study shows different results in terms of neck and wrist/hand/finger pain. Specifically, it was found that as farming duration increased, MSK pain decreased based on subjects' experience. In another study, Salik and Ozcan [27] found that physiotherapists in the early years of their careers tended to experience work-related MSK pain associated with lack of professional experience, and lower knowledge and skill levels reflected the importance of the skills acquired by experience. Additionally, Park et al. [28] suggested that older farmers might perform less physical labor with high levels of difficulty and high force tasks, as compared to younger farmers. Moreover, older experienced farmers may have learned to modify their work habits to avoid pain, discomfort, and injury.

There was a significant relationship between MSK symptoms and a history of acute injury. Most studies about work-related MSK disorders exclude MSK symptoms from acute injuries such as those caused by accidents $[9,10]$. However, as longevity increases, the chance of acute injuries in daily life increases. In cases of nonfatal injury, it is likely that people will return to their previous work. Hence, MSK symptoms due to acute injuries are highly likely to become chronic pain or recur among employees who are exposed to risks for MSK pain [29]. In this study, history of injury had a significant impact on MSK symptoms at the same injury site, with the exception of leg/foot pain. As a result, previous injuries is likely to make farmers suffer from related MSK pain on the ex- isting injured site [1].

In fact, only a few Korean farmers who suffer MSK pain sought periodic medical examinations and consulted a doctor [8], and farmers may not acknowledge symptoms as serious until they are unable to perform specific tasks [28]. In this study, many farmers received medical treatment but the rate of those without any medical intervention was considerably higher. This high burden of illness should be considered in planning healthcare services and setting research priorities.

This study had several limitations. First, self-reported health outcomes can include recall bias since farmers may not remember or may be inaccurate in recall, leading to the possibility of subjectivity in responses. Second, because we only considered the presence or absence of pain with respect to MSK symptoms, we could not diagnose MSK diseases. To check the exact factors that affect the MSK symptoms, objective analysis is a prerequisite. However, it would be unrealistic to use this method in such a large-scale study, which was why our study was based on subjective reporting of MSK symptoms. Third, questionnaires for presence of pain and level of workload rely on subjective answering, which affect each other, with reflecting the need for objective clarified measurements for pain or workload. Fourth, we investigated the side of pain without considering their dominant side, which may involve the increase of workload or severity of pain.

In conclusion, most Korean farmers experienced MSK pain, which was significantly associated with a history of prior injury and workload. Furthermore, females and younger farmers showed a high prevalence of MSK pain. These results suggest that farmers should be educated about the agricultural work-related MSK pain, risk factors, and prevention strategies. Additionally, for the effective management of agricultural work-related MSK pain, the development of preventive measures, surveillance systems for health problems, and strengthening insurance and compensation systems should be required at the government level. We presented the initial results of cohort study, and thus, we expect that serial changes in MSK pain with changes in sociodemographic, health characteristics and agricultural work-related conditions with suggestions on the scientific bases for coping and preventive strategies. 


\section{CONFLICT OF INTEREST}

No potential conflict of interest relevant to this article was reported.

\section{ACKNOWLEDGMENTS}

This study was supported by Research Grant for Center for Farmers' Safety and Health at Kangwon National University Hospital from Korean Ministry of Agriculture, Food and Rural Affairs.

\section{REFERENCES}

1. Rosecrance J, Rodgers G, Merlino L. Low back pain and musculoskeletal symptoms among Kansas farmers. Am J Ind Med 2006;49:547-56.

2. Lee CG. Work-related musculoskeletal disorders in Korean farmers. J Korean Med Assoc 2012;55:1054-62.

3. Park JH, Lim HS, Lee K. Work-related musculoskeletal symptoms among dairy farmers in Gyeonggi Province, Korea. J Prev Med Public Health 2010;43:205-12.

4. Walker-Bone K, Palmer KT. Musculoskeletal disorders in farmers and farm workers. Occup Med (Lond) 2002;52:441-50.

5. Lee KS, Kim HC, Chae HS, Kim KR, Lee SJ, Lim DS. A study on agricultural safety technology for ergonomic intervention in farm-work. J Ergon Soc Korea 2010;29:225-39.

6. Oh HO, Kam S, Han CH, Hwang BD, Mun HJ, Cha BJ, et al. Prevalence of musculoskeletal symptom in rural farmers. J Rheumatol Health 2001;8:86-108.

7. Kim K, Kim K, Kim H, Lee K. Risk assessment and symptoms of musculoskeletal disorders in melon farm workers. J Korean Soc Occup Environ Hyg 2006; 16:385-97.

8. Sun MH, Park IS, Jo GY. Survey of the musculoskeletal pain among farmers in the rural community. Korean J Rural Med 1991;16:40-7.

9. Lee K, Lim HS. Work-related injuries and diseases of farmers in Korea. Ind Health 2008;46:424-34.

10. Lee SJ, Kim I, Ryou H, Lee KS, Kwon YJ. Work-related injuries and fatalities among farmers in South Korea. Am J Ind Med 2012;55:76-83.

11. Korea Occupational Safety and Health Agency. Questionnaire for musculoskeletal symptoms. Guideline for evaluation of risk factors for musculoskeletal disorders (CODE H-30-2003). Seoul: Korea Occupational Safety and Health Agency; 2003.

12. Jo H, Baek S, Park HW, Lee SA, Moon J, Yang JE, et al. Farmers' Cohort for Agricultural Work-Related Musculoskeletal Disorders (FARM) study: study design, methods, and baseline characteristics of enrolled subjects. J Epidemiol 2016;26:50-6.

13. Cho TS, Jeon WJ, Lee JG, Seok JM, Cho JH. Factors affecting the musculoskeletal symptoms of korean police officers. J Phys Ther Sci 2014;26:925-30.

14. Yoo SW, Lee HE, Koh DH, Kim KS, Kim TW, Kim MG, et al. Relationship between musculoskeletal symptoms and non-fatal occupational injuries in construction workers in Korea. Korean J Occup Environ Med 2011;23:9-17.

15. Kim HJ, June KJ, Shin G, Choo J. Associations between job stress and work-related musculoskeletal symptoms in street sanitation workers. J Korean Acad Community Health Nurs 2013;24:314-22.

16. Kim H, Jeong WC. Gender difference in work-related musculoskeletal disease. Korean J Aerosp Environ Med 2004;14:142-50.

17. Hagberg M, Wegman DH. Prevalence rates and odds ratios of shoulder-neck diseases in different occupational groups. Br J Ind Med 1987;44:602-10.

18. Phajan T, Nilvarangkul K, Settheetham D, Laohasiriwong W. Work-related musculoskeletal disorders among sugarcane farmers in north-eastern Thailand. Asia Pac J Public Health 2014;26:320-7.

19. Osborne A, Blake C, Fullen BM, Meredith D, Phelan J, McNamara J, et al. Prevalence of musculoskeletal disorders among farmers: a systematic review. Am J Ind Med 2012;55:143-58.

20. Jensen C, Borg V, Finsen L, Hansen K, Juul-Kristensen B, Christensen H. Job demands, muscle activity and musculoskeletal symptoms in relation to work with the computer mouse. Scand J Work Environ Health 1998;24:418-24.

21. National Institute for Occupational Safety and Health. Musculoskeletal disorders and workplace factors: a critical review of epidemiologic evidence for workrelated musculoskeletal disorders of the neck, upper extremity, and low back (DHHS-97-141). Atlanta: National Institute for Occupational Safety and Health; 1997. 
22. Choi SY, Kim HS, Kim TH, Park DH. A study on job stress and MSDs (musculoskeletal disorders) of workers at automobile manufacturing industry. J Korean Soc Saf 2005;20:202-11.

23. Oliveira Dantas FF, de Lima KC. The relationship between physical load and musculoskeletal complaints among Brazilian dentists. Appl Ergon 2015;47:93-8.

24. Wijnhoven HA, de Vet HC, Picavet HS. Prevalence of musculoskeletal disorders is systematically higher in women than in men. Clin J Pain 2006;22:717-24.

25. Meekosha H, Jakubowicz A. Women suffering RSI: the hidden relations of gender, the labour process and medicine. J Occup Health Saf Aust N Z 1986;2:390401.

26. Kilbom A, Messing K. Work-related musculoskeletal disorders. In: Kilbom A, Messing K, Thorbjornsson CB, editors. Women's Health at Work. Solna: National Institute for Working Life; 1998. p. 203-27.

27. Salik Y, Ozcan A. Work-related musculoskeletal disorders: a survey of physical therapists in Izmir-Turkey. BMC Musculoskelet Disord 2004;5:27.

28. Park H, Sprince NL, Whitten PS, Burmeister LF, Zwerling C. Risk factors for back pain among male farmers: analysis of Iowa Farm Family Health and Hazard Surveillance Study. Am J Ind Med 2001;40:646-54.

29. Choi WJ, Kang YJ, Kim JY, Han SH. Symptom prevalence of musculoskeletal disorders and the effects of prior acute injury among aging male steelworkers. J Occup Health 2009;51:273-82. 